\title{
PRODUÇÃO DE ÉSTERES ETÍLICOS DERIVADOS DE ÁCIDO GRAXO VEGETAL EM BANHO DE ULTRASSOM EMPREGANDO COMO CATALISADOR LIPASE Candida antarctica B (CAL-B) IMOBILIZADA EM POLIURETANO.
}

\author{
R. P. SCHERER ${ }^{1}$; E. MORESCO ${ }^{1}$; C. M. TRENTIN ${ }^{2}$; N. L. D. NYARI ${ }^{1}$; D. de OLIVEIRA ${ }^{2}$; \\ J. V. de OLIVEIRA ${ }^{2}$. \\ 1-Departamento de Engenharia de Alimentos, URI - Campus de Erechim, \\ CEP: 99700-000, Erechim, RS, Brasil. \\ 2-Departamento de Engenharia de Alimentos UFSC, CEP:88040-900, Florianópolis, SC, Brasil. \\ rquimico@gmail.com
}

\begin{abstract}
RESUMO - O presente trabalho visa na produção enzimática de ésteres etílicos em banho de ultrassom em modos batelada e contínuo empregando a lipase Cal-B imobilizada em poliuretano e ácido graxo vegetal de soja. Os experimentos foram realizados em tempos reacionais de 5 a 360 minutos, razão molar (ácido graxo/ etanol) 1:6, $65^{\circ} \mathrm{C}, 10 \%$ (m/m) de enzima imobilizada CALB, potências de 0 e 132 Watts, para os modos batelada e contínuo. Para modo continuo usou-se vazão de alimentação de $2,5 \mathrm{~mL} / \mathrm{min}$. Verificou-se que a potência do ultrassom no modo batelada apresentou influência positiva na conversão em ésteres etílicos com conversões em torno de $83 \%$ quando comparado ao seu não uso $56 \%$ no mesmo tempo reacional. Entretanto o modo contínuo demonstrou-se menos mais eficaz com conversões na faixa de $45 \%$ em ésteres, em quase todo o processo reacional. Este resultado deve-se a possível formação de glicerol dentro do reator, aderindo sobre o suporte enzimático e diminuindo a atividade catalítica da enzima.
\end{abstract}

\section{INTRODUÇÃO}

A produção de biodiesel apresenta-se hoje como uma solução ambientalmente correta e significativa na geração de energia limpa. A transesterificação de fontes oleaginosas, conduz à diminuição da viscosidade do óleo vegetal melhorando assim o desempenho do mesmo em motores movidos a diesel. Atualmente, o biodiesel é obtido através de reações de transesterificação entre um óleo vegetal e um álcool de cadeia curta na presença de catalisador. (Demirbas, 2007).

A síntese de biodiesel com base em fontes vegetais não comestíveis e óleos residuais têm sido desenvolvidos, entretanto a grande quantidade de ácidos graxos livres e umidade excessiva presentes nestas fontes requer o uso de um processamento adicional, aumentando o tempo reacional e consumindo muita energia. $\mathrm{O}$ emprego de processos e técnicas com o objetivo de fazer a síntese de biocombustíveis ser economicamente viável ganha espaço, e uma destas abordagens baseia-se no uso de reatores sonoquímicos (Stavarache et al., 2005). 


\section{9 a 22 de outubro de 2014 \\ Florianópolis/SC}

O processo de produção enzimática de biodiesel em ultrassom vem como alternativa ao processo convencional empregando-se agitação mecânica, uma vez que as cavitações (formação, aumento e implosão de bolhas no meio reacional) geradas pelo ultrassom, aumentam a miscibilidade entre os reagentes, fornecem energia necessária para a reação, reduzem o tempo de reação e a quantidade de reagentes empregadas no processo, além disso, aumentam o rendimento e a seletividade da reação (Yu et al., 2010).

Segundo Veljkovic et. al.,(2012) poucos trabalhos são encontrados na literatura acerca da influencia do ultrassom nas reações enzimáticas para produção de biodiesel. Trabalhos utilizando Novozym 435 foram testados em estudos com ultrassom e alcoóis para reação de transesterificação de óleo de soja e resíduos de óleos com índice de acidez elevados (Yu et al., 2010; Lin et al., 1995; Sinisterra, 1992) relatando que a atividade da enzima nas reações de transesterificação é aumentada pela intensidade das ondas irradiadas pelo ultrassom.

Existem dois processos básicos para síntese de biodiesel, batelada e contínuo, que podem ser realizados a temperatura ambiente ou mais elevadas, a pressão atmosférica, na presença ou ausência de catalisadores adequados. O processo contínuo proporciona um menor custo de produção, a qualidade do produto é uniforme, facilita o controle do processo diminuindo o volume do reator, reduzindo o tempo de retenção necessária para atingir conversões desejadas. (Veljkovic et.al. 2012).

Desta forma, o presente estudo é uma sequência do trabalho desenvolvido pelo grupo de pesquisa e descrito por Trentin et.al (2014), empregando a lípase comercial Novozym 435. Assim este agora visa o estudo da produção de ésteres etílicos em ultrassom utilizando como substrato um ácido graxo vegetal proveniente de óleo de soja e alcóol etilico em modos de processo batelada e contínuo, empregando como catalisador a lipase Candida antarctica tipo B (Cal-B) imobilizada em espuma de poliuretano.

\section{MATERIAL E MÉTODOS}

\subsection{Materiais}

Nas reações de transesterificação utilizou-se como substrato, ácido graxo vegetal de soja obtido da SGS Agricultura e Industria LTDA de Ponta Grossa - PR, com índice de acidez de 199,8 $\mathrm{mgKOH} / \mathrm{g}$ e composição química: (10,9\% ácido palmítico, 3,5\% ácido esteárico, 26,1\% ácido oleico, 52,7\% ácido linoléico e 5,1\% ácido linolênico), álcool etílico (Merck, 99,9\% de pureza) e a enzima Candida antarctica B (Cal-B), imobilizada em espuma de poliuretano.

Para a determinação da atividade enzimática os seguintes reagentes/solventes foram utilizados: acetona P.A ACS (Vetec, 99,5\%), álcool etílico (Merck, 99,9 \% de pureza). Ácido Óleico (Sigma Aldrich, 99\% CG) e álcool etílico (Merck, P.A). Os experimentos para produção enzimática de biodiesel em modos batelada e contínuo foram realizados em um banho de ultrassom (Unique ultrasonic Cleaner, modelo: USC-1800A, frequência US: 40KHz, potência US: 132W). 


\subsection{Métodos}

Procedimento experimental: Com base em trabalhos anteriores realizados pelo nosso grupo de pesquisa (Trentin et.al. 2014, Scherer et.al. 2013a), o estudo comparativo deste trabalho entre os processos em modos batelada e contínuo, foram realizados utilizando razão molar (ácido graxo/ etanol) $1: 6,10 \%(\mathrm{~m} / \mathrm{m})$ de enzima CALB, em relação à massa total de substratos (ácido graxo + etanol), temperatura $65^{\circ} \mathrm{C}$, potências ultrassônicas (0 Watts e 132 Watts), equivalente a $0 \%$ e $100 \%$ da potência do equipamento. Para o modo batelada os experimentos foram realizados em balão de $50 \mathrm{~mL}$ conforme Figura 1(a).

No modo contínuo, além destas condições experimentais apresentadas anteriormente o sistema experimental utilizado consistiu num reator de polietileno de alta densidade (com 1/16 $\mathrm{mm}$ de diâmetro externo, espessura de $1,1 \mathrm{~mm}$, diâmetro interno de $4,15 \mathrm{~mm}$, comprimento de 2 metros e volume total de $27 \mathrm{~mL}$ conforme apresentado na Figura 1(b) com vazão de alimentação de $2,5 \mathrm{~mL} / \mathrm{min}$ da mistura reacional carga ácida/etanol, e o reator empacotado com aproximadamente $8 \mathrm{~g}$ de catalisador, sendo este a enzima Candida antarctica B (CALB) imobilizada em espuma de poliuretano. O tempo espacial da $1^{\mathrm{a}}$ gota percorrido pela mistura reacional no reator ocorreu após 13 minutos de reação, sendo realizadas coletas de amostras para análise a cada 5,5 minutos conforme trabalhos anteriores (Scherer et.al. 2013).

Figura 1 - Reação de transesterificação em modos batelada (a) e contínuo (b).

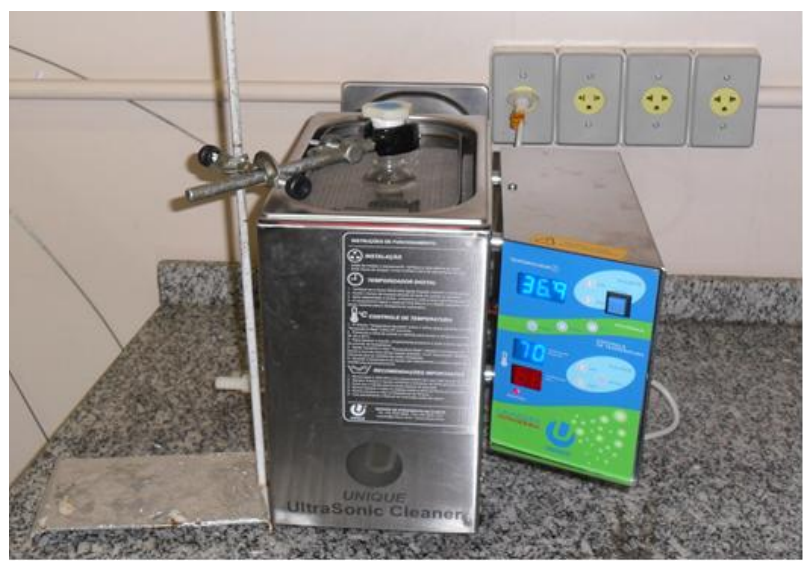

(a)

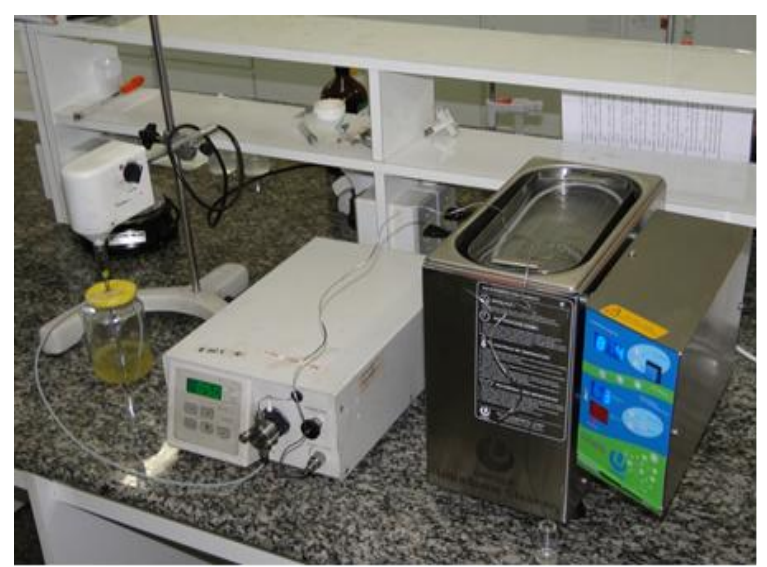

(b)

Neste estudo como a reação de esterificação produz além dos ésteres também água, as amostras coletadas foram analisadas através do método de titulação verificando a conversão dos ácidos graxos produzidos (Trentin et. al. 2014). Este é um método eficiente que substitui, neste caso, a utilização da cromatografia gasosa na quantificação dos ácidos graxos, sem a necessidade de secagem para a completa remoção da água presente na amostra e não necessitando também da evaporação do excesso de álcool remanescente no meio.

A técnica da titulação foi realizada de acordo com a IUPAC 2.201 o AOCS Cd 3d - 63 e consiste na determinação da acidez do meio reacional devido a presença dos ácidos graxos livres. 


\section{RESULTADOS E DISCUSSÃO}

\subsection{Produção de biodiesel: modo batelada versus modo contínuo.}

Nas reações de transesterificação existem dois procedimentos básicos para a síntese de biodiesel, modo batelada e contínuo, que podem ser realizados a temperatura ambiente ou mais elevadas, à pressão atmosférica ou elevada e na presença ou ausência de catalisadores adequados.

No método batelada, as fases de reação e da separação são geralmente efetuadas no mesmo tanque, de modo que requer um maior volume do reator e tempos de reação e separação mais longos (Thanh et al., 2010).

O processo contínuo proporciona um menor custo de produção, a qualidade do produto é uniforme, facilita o controle do processo e diminuindo o volume do reator, reduz-se o tempo de retenção necessário para atingir conversões desejadas (Veljkovic et al., 2012).

A fim de realizarmos um comparativo entre os dois modos de produção de biodiesel, realizaram-se quatro testes conforme apresentados nas Figuras 2 e 3. Através dos mesmos, é possível verificar claramente que a potência ultrassônica apresenta influência na produção de ésteres etílicos para o modo de produção batelada. Já para o modo continuo percebe-se que o ultrassom não demonstra influência sobre o processo apresentando conversões semelhantes.

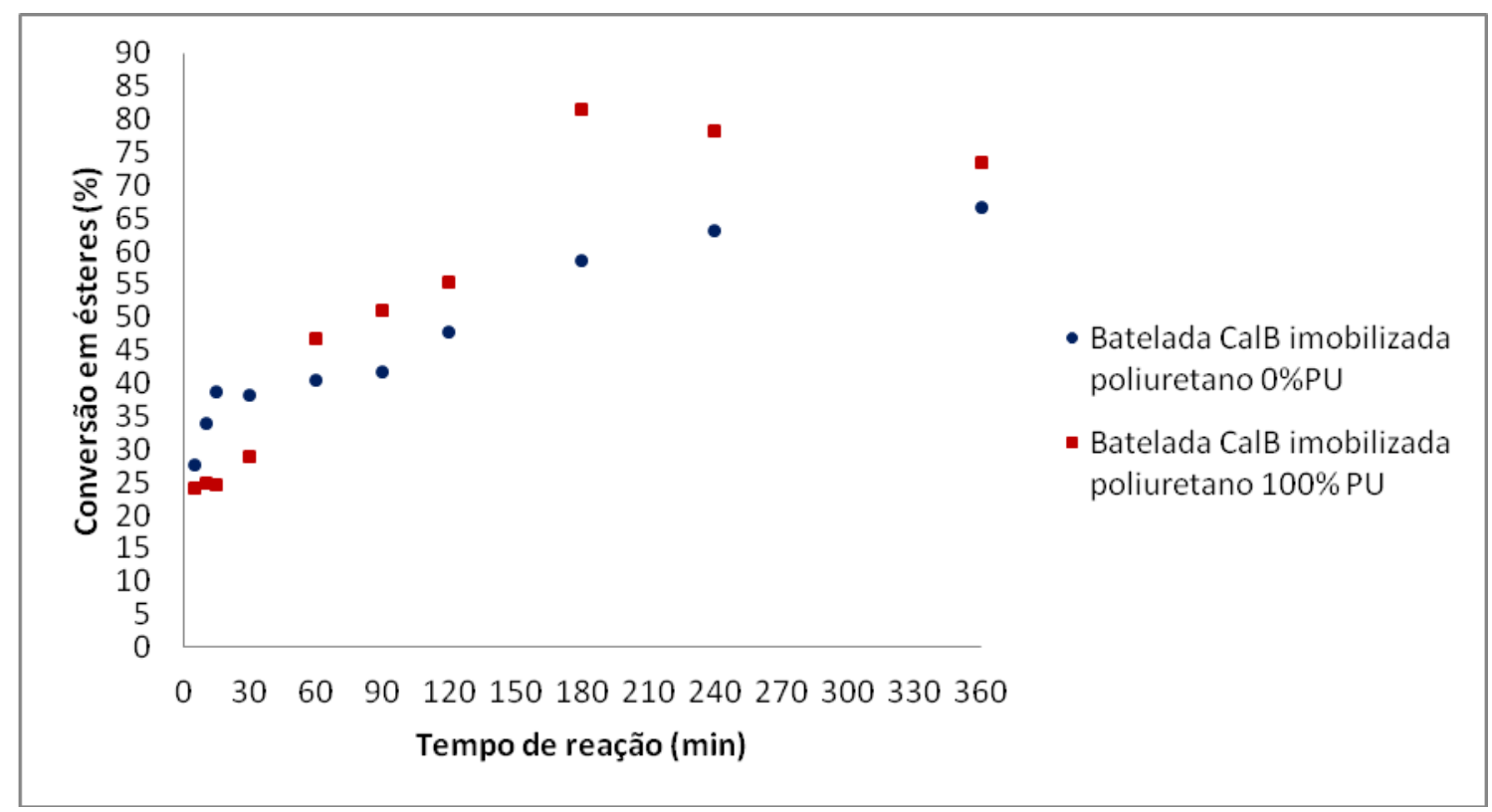

Figura 2 - Conversão em ésteres etílicos derivados de ácido graxo vegetal em modo batelada com potências ultrassônicas (PU) 0 Watts (0\%) e 132 Watts (100\%). 


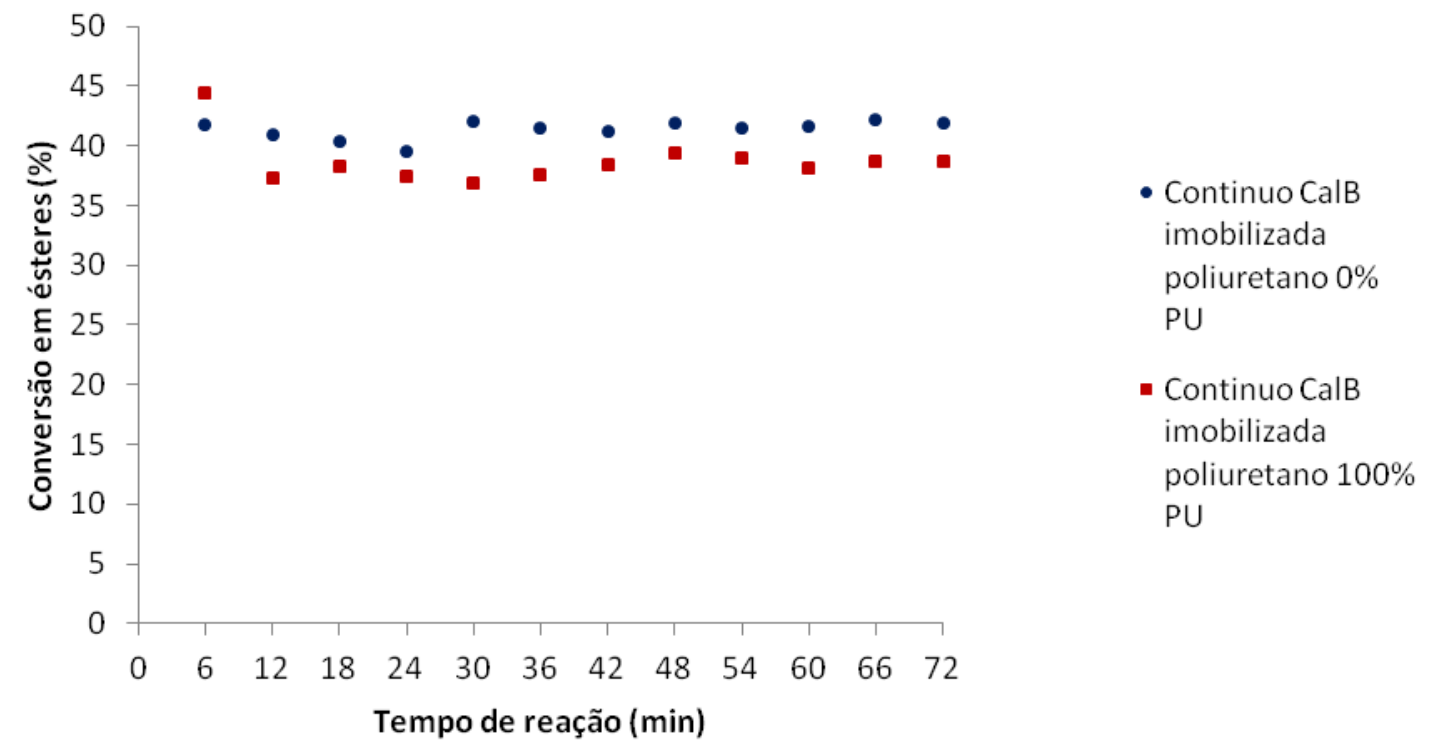

Figura 3 - Conversão em ésteres etílicos derivados de ácido graxo vegetal em modo contínuo com potências ultrassônicas (PU) 0 Watts (0\%) e 132 Watts (100\%).

Em relação às atividades enzimáticas, a atividade inicial da enzima CALB utilizada foi de $561,40 \mathrm{U} / \mathrm{g}$ e as atividades após reações para o modo batelada a 0 e 132 Watts foi respectivamente de 479,18 U/g e 367,23 U/g, já para o modo contínuo de produção de ésteres etílicos a atividade final após reações de transesterificação foi de 393,4 U/g e 274,71U/g para as potências de 0 e 132 Watts.

A partir destes resultados percebe-se que ocorreu uma redução da atividade da enzima em ambos os processos utilizados, porém para o modo contínuo essa redução foi maior ao utilizarmos a potência do ultrassom.

Ao realizarmos uma comparação entre os dois modos (batelada e contínuo) verifica-se por meio das Figuras 3 e 4 que o modo batelada apresenta-se mais eficaz que o modo continuo sendo que para a produção de biodiesel em modo batelada com o uso de potência ultrassônica (132 Watts) obtém-se conversões em ésteres de $83 \%$ em tempo reacional de 180 minutos, neste mesmo tempo sem o uso do ultrassom (0 Watss) obteve-se conversão em ésteres bem inferior $56 \%$. Em modo continuo percebe-se que tanto com o uso de potências de 132 e 0 Watts as conversões durante todo o processo foram na faixa de $45 \%$ em ésteres. Este resultado provavelmente deve-se ao processo de redução da atividade catalítica da enzima, ocasionada pela incrustração do glicerol formado durante a reação, na superfície do suporte da lipase levando assim o impedimento ao acesso do substrato ao sitio ativo da enzima diminuindo sua atividade catalítica e consequentemente reduzindo o rendimento final em ésteres. 


\section{CONCLUSÕES}

Ao final deste trabalho percebe-se que a potência do ultrassom exerce influência sobre a conversão em ésteres etílicos quando empregada em modo batelada mostrando assim como uma perspectiva promissora para o uso desta técnica.

Comparando a produção de biodiesel em modo batelada e em reator contínuo, pode-se concluir que o método batelada é efetivamente melhor, com conversões em éstes na ordem de $83 \%$ em período de tempo de 180 minutos. No modo continuo esses resultados foram bem inferiores (45\%), devido à diminuição da atividade catalítica da enzima ocasionada pela possível formação de glicerol dentro do reator, aderindo este sobre o suporte enzimático.

\section{REFERÊNCIAS}

DEMIRBAS. A. Importance of biodiesel as transportation fuel. Energy Policy. v. 35, 4661-4670, 2007.

LIN, G.; LIU, H. Ultrasound promoted lipase catalyzed reactions. Tetrahedron Lett, 36(34) p. 6067-8, 1995.

SINISTERRA, J. V. Application of ultrasound to biotechnology: an overview. Ultrasonics, v. 30, p. 180-184, 1992.

SCHERER, R.P.; TRENTIN, C.M.; ZANATTA, J.; LEVANDOSKI; K.; DALLA ROSA; C.; OLIVEIRA; D.; OLIVEIRA; J.V. Emprego de tecnologia ultrassônica para produção de biodiesel enzimático. VIII Simpósio de Alimentos, v. 8, 1-6, Passo Fundo-RS, Outubro, 2013.

SCHERER, R.P.; TRENTIN, C.M.; ZANATTA, J.; LEVANDOSKI; K.; DALLA ROSA; C.; OLIVEIRA; D.; OLIVEIRA; J.V. Estudo da produção de biodiesel via rota enzimática empregando ácido graxo vegetal em sistema de ultrassom livre de solvente. $17^{\circ}$ Congresso Brasileiro de Catálise, VII Congresso de Catálise do Mercosul, Gramado-RS, Setembro, 2013

STAVARACHE, C.; VINATORU, M.; NISHIMURA, R.; MAEDA, Y. Fatty acids methyl esters from vegetable oil by means of ultrasonic energy. Ultras. Sonochem. v. 12, 367-372, 2005.

THANH; L.T.; OKITSU; K.; SADANAGA; Y.; TAKENAKA; N.; MAEDA; Y.E.; BANDOW, H. A two-step continuous ultrasound assisted production of biodiesel fuel from waste cooking oils: A practical and economical approach to produce high quality biodiesel fuel. Bioresour. Technol. v. 101, 5394-5401, 2010.

TRENTIN; C.M.; SCHERER; R.P.; DALLA ROSA; C.; TREICHEL; H.; OLIVEIRA; D.; OLIVEIRA; J.V.; Continuous lípase-catalyzed esterification of soybean fatty acids under ultrasound irradiation. Bioprocess Biosyst Eng, v. 37, 841-847, 2014. 
YU, D.; TIAN, L.; WU, H.; WANG, S.; WANG, Y.; MA, D.; FANG, X. Ultrasonic irradiation with vibrationfor biodiesel production from soybean oil by Novozym 435. Process Biochemistry, v. 45, 519-525, 2010.

VELJKOVI'C, V.B.; AVRAMOVI'C, J.M.; STAMENKOVI'C, O.S. Biodiesel production by ultrasound-assisted transesterification: State of the art and the perspectives. Renew. Sustain. Energy Rev. v. 16, 1193-1209, 2012. 